\title{
QUEEN'S
UNIVERSITY
BELFAST
}

\section{Gold nanoparticle surface functionalization: a necessary requirement in the development of novel nanotherapeutics}

Nicol, J. R., Dixon, D., \& Coulter, J. A. (2015). Gold nanoparticle surface functionalization: a necessary requirement in the development of novel nanotherapeutics. Nanomedicine, 10(8), 1315-1326.

https://doi.org/10.2217/nnm.14.219

\section{Published in:}

Nanomedicine

Document Version:

Early version, also known as pre-print

Queen's University Belfast - Research Portal:

Link to publication record in Queen's University Belfast Research Portal

\section{Publisher rights}

Copyright 2015 Future Medicine.

This work is made available online in accordance with the publisher's policies. Please refer to any applicable terms of use of the publisher.

\section{General rights}

Copyright for the publications made accessible via the Queen's University Belfast Research Portal is retained by the author(s) and / or other copyright owners and it is a condition of accessing these publications that users recognise and abide by the legal requirements associated with these rights.

Take down policy

The Research Portal is Queen's institutional repository that provides access to Queen's research output. Every effort has been made to ensure that content in the Research Portal does not infringe any person's rights, or applicable UK laws. If you discover content in the Research Portal that you believe breaches copyright or violates any law, please contact openaccess@qub.ac.uk. 


\title{
Gold Nanoparticle Surface Functionalisation - A Necessary Requirement in the Development of Novel Nano-Therapeutics
}

\author{
Nicol, JR ${ }^{1}$, Dixon $\mathbf{D}^{2}$, Coulter $\mathbf{J A}^{1}$ \\ ${ }^{1}$ School of Pharmacy, McClay Research Centre, Queen's University Belfast, UK \\ ${ }^{2}$ School of Engineering, Jordanstown campus, University of Ulster, UK.
}

Corrosponding author: j.coulter@qub.ac.uk

\section{Summary}

With several gold nanoparticle based therapies currently undergoing clinical trials, these treatments may soon be in the clinic as novel anti-cancer agents. Gold nanoparticles are the subject of a wide ranging international research effort with preclinical studies underway for multiple applications including photoablation, diagnostic imaging, radiosensitisation and multi-functional drug delivery vehicles. These applications require an increasingly complex level of surface modification in order to achieve efficacy and limit off-target toxicity. This review will discuss the main obstacles in relation to surface functionalization and the chemical approaches commonly utilised. Finally we review a range of recent pre-clinical studies that aim to advance gold nanoparticle treatments towards the clinic.

Keywords: gold, nanoparticle, biological barrier, nanoparticle stability, organelle targeting, nanoparticle functionalization.

\section{Introduction}

While modern medicine has substantially increased overall life expectancy, ageing populations exhibit a greater risk of developing complex cancers resistant to conventional therapeutics. This highlights the need for the development of effective, novel interventions. The rapidly expanding field of nanomedicine offers the promise of increasing the efficacy of existing therapies, along with the development of novel 
therapeutics to target specific sites. Nanoparticle variables such as size, shape and surface charge have all been shown to strongly influence therapeutic efficacy by altering endocytotic potential and functional surface area. Nanoparticles are defined as particles between 1-1000 $\mathrm{nm}$ [1] which possess a range of unique properties supporting a variety of applications including drug delivery, imaging, biosensors and therapies [2]:[3]:[4]. Gold nanoparticles (GNPs) are one of the most widely studied preparations, due to their perceived bio-compatibility and tuneable surface chemistry highlighted by the relative ease with which additional functional groups can be conjugated. This review will detail the various chemistries used to functionalise GNPs and will provide a detailed overview of recent developments in both pre-clinical and clinical progression.

\section{Gold Nanoparticles}

Gold nanoparticles (GNPs) have been investigated as both diagnostic and therapeutic agents, utilised as potential delivery vectors, CT-contrast agents and therapeutics in their own right[5]. To date GNPs have featured in two clinical trials: CYT-6091, a GNP conjugated to polyethylene glycol (PEG) and recombinant human tumour necrosis factor alpha (rhTNF)[6], which possess both cytotoxic and immunomodulatory effects. In this case, rhTNF acts as both a targeting ligand and a therapeutic agent. This small phase I study commenced in 2005 where 29 patients with solid tumours demonstrated no dose-limiting toxicity up to $600 \mu \mathrm{g} \mathrm{m}^{-2}$, with controllable grade II fever reported as the main side-effect. One partial response and 3 stable disease states were observed, demonstrating a positive outcome in $14 \%$ of patients. A second GNP clinical trial plans to use AuroShell ${ }^{\circledR}$ particles (Nano-spectra Biosciences Inc, Houston, TX) administered intravenously, followed by exposure to an $808 \mathrm{~nm}$ laser as photothermal ablation therapy for the treatment of head and neck cancer[7]. In vivo data from the same study demonstrated that the $155 \mathrm{~nm}$ nanoshells capped with $5000 \mathrm{M}_{\mathrm{w}}$ PEG have the ability to accumulate at the tumour site in canines with brain tumours; human trials are ongoing as of September 2014. GNPs have also been used as effective radiosensitising agents, an application initially observed using gold microfoils[8]. Subsequently, $1.5-3 \mu \mathrm{m}$ gold microspheres generated a radiation dose 
enhancement factor of 1.43 in the presence of $1 \%$ gold particles[9]. In order to develop clinically relevant GNP based therapeutics or diagnostic agents, the addition functional surface groups are generally deemed necessary. Functional groups are typically used to increase stability, limit immune cell responses, increase drug loading, actively target tumours, increase target cell uptake or to preferentially direct nanoparticle accumulation within specific sub-cellular compartments. The complexity, reproducibility and up scaling issues associated with the attachment of functional groups highlight a few of the major challenges limiting the clinical exploitation of GNPs.

\section{Chemical Synthesis of Gold Nanoparticles}

A detailed understanding of the chemistry required to accurately synthesise and functionalise GNPs is a prerequisite in the development of successful nanoparticle therapeutics. The most common protocol for GNP synthesis is the Turkevitch[10] method, later amended by Frens[11]. Briefly, this can be described as the reduction of boiling chloroauric acid $\left(\mathrm{HAuCl}_{4}\right)$ with trisodium citrate dihydrate while vigorously stirring. This produces a red liquid, with GNPs formed with core sizes between $15-100 \mathrm{~nm}$ dependant on the ratio of trisodium citrate to $\mathrm{Au}$, where higher concentrations of citrate yield smaller stable GNPs. Conversely, lower concentrations of trisodium citrate lead to larger nanoparticles and aggregation[12]. Nanoparticle size control using low concentrations (Au/citrate ratio above 0.86) of citrate is unreliable above $\sim 35 \mathrm{~nm}$, typically resulting in a wide bi-modal size distribution containing a proportion of large non spherical GNPs[13]. Despite this, citrate stabilised GNPs are typically larger than $10 \mathrm{~nm}$ due to the moderate reducing ability of trisodium citrate dihydrate. Interestingly the use of heavy water $\left(\mathrm{D}_{2} \mathrm{O}\right)$ as the solvent instead of $\mathrm{H}_{2} \mathrm{O}$ permits the synthesis of citrate-capped nanoparticles as small as $5 \mathrm{~nm}$, due to $\mathrm{D}_{2} \mathrm{O}$ increasing the reducing potency of citrate[14]. In the Turkevich method, the citrate acts as both a reducing agent and a capping agent yielding negatively charged GNP with a $\zeta$ potential of $\sim 20-40 \mathrm{mV}[13]$. This leads to an electrostatically stabilised suspension since the equivalent charges on the GNPs tend to repel each other. The citrate capping is loosely bound on the GNP, enabling it to be easily replaced with other functional groups. In addition to the traditional use 
of sodium citrate, GNPs have also been synthesised from $\mathrm{HAuCl}_{4}$ using ultrasonic irradiation, micro plasmas and plant extracts as reducing agents[15],[16],[17]. GNPs have also been produced using $\mathrm{NaOH}$ and polyvinylpyrrolidone (PVP) yielding functionalised nanoparticles that are non-toxic at high concentrations $(100 \mu \mathrm{M})[18]$

The Brust-Schiffrin method allows synthesis of thiolate-stabilised GNPs $<5 \mathrm{~nm}$, producing nanoparticles with high thermal and air stability properties, which are highly reproducible and easy to manipulate through surface ligand substitution[19]. The synthesis of smaller GNPs through the Brust method is attributed to sodium borohydride $\left(\mathrm{NaBH}_{4}\right)$ being a stronger reducing agent than sodium citrate, producing a higher reaction rate and thereby yielding a smaller GNP[19]. This step-by-step chemical process has previously been described by Li et al (2011) following extensive Raman specroscopy[20]. Since GNPs produced using $\mathrm{NaBH}_{4}$ are not capped with the reducing agent as is the case with the Turkevich method, a separate capping agent must be used during synthesis. Long-term stabilization has been reported with GNPs non-covalently stabilized by benzyldimethyltetradecylammonium chloride, with nanoparticles maintaining their size over subsequent months[21]. The requirement to use a separate capping agent during synthesis makes any subsequent surface modification of these GNP more problematic than is the case with citrate capped GNPs. Both the Turkevitch/Frens and Brust-Schiffrin method can be seen in figure 1. Alternate GNP synthesis methods also exist, including pulse radiolysis and top-down methods which have been discussed in greater detail by Zhao et al [19]. In addition to spherical GNPs is it also possible to produce nanorods and nanowires. This allows tuning of the GNP's IR absorbance characteristics, which is beneficial for photoablation applications. Nanorod synthesis can be achieved using aromatic additives, thereby reducing the concentration of hexadecyltrimethylammonium bromide (CTAB) from 0.1 M to $0.05 \mathrm{M}$ compared to the well-established seed-mediated synthesis method granting better control over monodispersity and spectral tunability[22].

\section{Functionalization of Gold Nanoparticles}


Functionalization of citrate capped GNPs is relatively easy due to the weakness of the Au-citrate interaction which is electrostatic in nature and can be substituted with stronger thiolated ligands simply by reacting the GNP with the relevant functional thiols under ambient conditions. Thiol linkers have been used to attach a wide range of ligands to GNPs including: polymers e.g. polyethylene glycol (PEG)[23], fluorescing dyes including Bodipy[24], and drugs such as Paclitaxel[25]. Peptides can also be attached directly to the GNP surface using the thiol group on a cysteine unit or by means of the $\mathrm{N}$ terminal primary amine[26],[27]. GNPs capped using thiol chemistry have been widely studied with a range of therapeutic applications, including drug delivery and medical imaging[28],[29]. The thiol bound surfactant used to stabilise GNPs prepared via $\mathrm{NaBH}_{4}$ reduction can be replaced with other thiol terminated groups provided the functional group is compatible with reaction conditions[30]. The ligand exchange reaction is typically conducted at room temperature in a solvent such as toluene over a period of several days[31]. However, there are drawbacks to this method including an increased chance of irreversible nanoparticle aggregation, difficulty in determining the exact amount of exchanged ligand and the potential for incomplete ligand substitution. One effective approach for ligand replacement is to replace a ligand loosely bound to the GNP via a citrate or phosphine attachment with a thiol terminated ligand. The reaction at the GNP surface, between a thiol group and the GNP results in the Au replacing the hydrogen from the thiol group. An alternate method 'Click' chemistry typically refers to the Husigen 1,3-dipolar cyloaddition of azides and terminal amides providing fast, simple and irreversible reactions for the attachment of structural units, and has also been used for GNP functionalization [32]. Boisselier et al (2010) used 'click' chemistry to successfully synthesize encapsulate and stabilize GNPs with PEG dendrimers using a variety of reduction methods including $\mathrm{NaBH}_{4}$ in methanol[33]. Highly functionalized GNPs are achievable through this technique with Gadolinium ${ }^{\text {III }}$ enriched DNA-GNP conjugates being formed, which demonstrating high HeLa cell uptake for magnetic resonance imaging[34].

GNPs can also be functionalised electrostatically, for example a positively charged ligand would be attracted to the negatively charged citrate capping on a Turkevich synthesised GNP. This type of attachment in which the ligand mixes with the citrate layer is also referred to as physisorption and 
relies upon electrostatic and Van Der Walls effects. This approach can be used to form the selfassembly of nanoparticle structures and functionalizations in solution[35]. However, the approach has several shortcomings, it is only suitable for use with appropriately charged ligands, the ligands are not attached in a particular orientation making the biological response difficult to control and the binding is affected by changes in $\mathrm{pH}$.

In order to create a GNP therapy or diagnostic suitable for clinical use it is typically necessary to cofunctionalise the GNP with a number of ligands for specific functions. These ligands are typically attached to the surface of the GNPs in the form of a mixed monolayer, with common formulations including PEG and peptides[36] PEG and fluorescing dye[24] or PEG with other heavy metal atoms[37]. Mixed monolayers of alcohol-terminated PEG have been highlighted for in vivo applications, featuring no toxicity, no immune response and high water solubility and stability[38]. Such mixed monolayer coatings can be easily prepared from GNPs produced via citrate reduction by first reacting the GNP with an appropriate amount of thiolated PEG to produce an incomplete layer and then subsequently reacting the partially capped GNP with another suitability terminated ligand. In a seminal study, leading to the previously mentioned CYT-6091 human trials, Paciotti et al (2006) showed tumour specific GNP uptake, a reduction in tumour volume and increased survival in an animal study of GNPs functionalised with a mixed monolayer containing Thiolated PEG and electrostatically bound TNF[39]. An alternate approach is to attach the required ligands to the GNP by means of a linker molecule. In this arrangement the GNP surface is fully functionalised with a polymer chain such as PEG or a short chain hydrocarbon (e.g. octadecathiol). The required ligand is then attached to the other end of the linker chain. This could be referred to as sequential functionalization as one ligand is attached to the end of another. The linker chain provides the required stability while the functional ligand attached to the free end is readily available for biological interaction. For example, Brown et al (2010) functionalized GNPs with thiolated PEG which had a carboxylate end group. This free end group was then reacted with the platinum group on oxaliplatin, a widely used chemotherapy agent[40]. It was observed that these functionalised GNPs were internalised by human lung cancer cells and showed a 5.7 fold increase in cytotoxicity compared to 
free oxaliplatin. In another study GNPs which were functionalized with thiol-PEGylated tamoxifen were found to selectively target human breast cancer cells demonstrating much greater potency than the free drug[41].

\section{Gold Nanoparticle Stability}

Chemical synthesis of GNPs typically requires the inclusion of a capping agent such as sodium citrate to provide stability in a $\mathrm{pH}$ neutral solution, such as water or PBS (phosphate-buffered saline) through electrostatic repulsion. However problems persist with aggregation upon $\mathrm{pH}$ change and non-specific adsorption of serum proteins to the nanoparticle surface, resulting in rapid removal through the reticuloendothelial system (RES). The most widely studied agent is polyethylene glycol (PEG), an ethylene oxide polymer of varying lengths that provides enhanced stability and increased systemic circulation. This hydrophilic polymer creates a steric barrier reducing the attachment of serum proteins (also known as opsonisation). This effectively eliminates the primary mechanism for identification by the RES (e.g. the scavenger receptor on Kupffer cells in the liver), thereby increasing bio-availability and tumour specific accumulation[42]. Passive nanoparticle accumulation within a tumour volume is primarily driven by the enhanced permeability and retention effect (EPR), where the torturous nature of the vasculature, and the poor lymphatic drainage result in the transit of nanoparticles of up to 500 $\mathrm{nm}$ across the vascular endothelium into the tumour interstitium[43]. Longer PEG chains confer improved stability but also hinder intracellular uptake of the nanoparticle limiting therapeutic benefit[44],[45]. As an alternative to the chemical synthesis of GNPs and addition of PEG through a ligand exchange process a more controlled synthesis can be achieved through laser ablation excluding the need for a capping agent, as such a higher density of PEGylation can be achieved. This approach will permit the use of shorter PEG chains, reducing steric hindrance and potentially increasing stability[46]. Further functionalization with the sequential inclusion of a targeting peptide to the outward facing terminal of the PEG resulted in an intracellular concentration of up to $11 \mathrm{pg} / \mathrm{cell}$ in U-

87MG cells, 18-fold higher than its non-targeted comparison. ${ }^{32}$ Mixed PEG layers, prepared using 
specific ratios of low- and high-molecular weight PEG chains, were conjugated to proteins and monoclonal antibodies using standard carbodiimide chemistry without detectable aggregation. This study demonstrated that a compromise can be achieved between the excellent steric protection provided by thick PEG layers and the high bioconjugation yields afforded by layers from low-molecular weight PEG[47].

Alternative stability strategies exist with varying levels of success and practicality. 16-100 nm GNPs functionalised with mixed charged zwitterionic self-assembled monolayers with a 1:1 molar ratio mixture of negatively charged sodium 10-mercaptodecanesulfonic acid (HS-C10-S) and positively charged (10 mercaptodecyl)-trimethyl-ammonium bromide (HS-C10-N4) showed good stability in cell media with $10 \%$ FCS and strong resistance to protein adsorption. Interestingly $100 \mathrm{~nm}$ GNPs demonstrated improved stability over mercaptopolyethylene glycol (Mw = 2000, HS-PEG2000) over 6 months[48]. Despite significant progress in nanoparticle stability, questions remain as to whether the ethylene glycols are the best option despite being the most frequently utilised. In addition the length and density of stability functionalization remains highly contested with no one optimal configuration, a factor primarily dictated by the impact of additional functional groups.

\section{Cellular Uptake of Gold Nanoparticles}

The mechanism for GNP uptake has been debated, with the most likely mechanism being energy dependent, non-specific receptor mediated endocytosis $(\mathrm{RME})^{36}$. In vivo, non-specific serum protein adsorption is believed to largely define the biological identity of the nanoparticles, while properties such as the nanoparticle geometry influence the specific endocytotic pathway. Clathrin-dependant endocytosis is believed to be the dominant uptake pathway for spherical particles, while those with larger dimensions are predominantly internalised by macropinocytosis and phagocytosis[49]. Figure 2 shows cellular uptake of spherical $1.9 \mathrm{~nm}$ GNPs through clathrin-dependant endocytosis[50]. However, a simplified one-size fits all approach is overly simplistic, with numerous reports detailing differential optimal uptake characteristics between tumour types of various origins[51],[52]. 
GNP functionalization with cell-penetrating peptides and specific targeting antibodies represent one area of particular interest. This approach has been employed to increase the targeting specificity of chemotherapy conjugated in an effort to avoid off-target toxicity. TAT peptides, derived from the transcriptional activator protein encoded by the human immunodeficiency virus type 1 (HIV-1) is a frequently used cell-penetrating peptide (CPP). Yuan et al (2012) reported TAT-functionalized gold nanostars entering the cell through actin-driven lipid raft-mediated micropinocytosis[53]. TAT also enhanced uptake of gold nanostars relative to unconjugated particles, within $1 \mathrm{~h}$ of incubation on BT549 breast cancer cells. This enhanced level of uptake expanded the potential applications of the nanostars, as diagnostic agents and therapeutics using photodynamic therapy[54]. A wide range of CPP's exist with various motifs, typically consisting of 12-30 amino acids with a net positive charge to encourage electrostatic interaction with the negatively charged cell membrane[55]. Table 1 details the origin and sequence of some commonly utilised cell penetrating peptides.

Actively targeted nanomedicines may prove more beneficial than those which depend upon passive accumulation. The human epidermal growth factor receptor 2 (HER2) receptors are overexpressed in $25 \%$ of breast cancer cases, making this subset of breast cancers an ideal target for therapeutic GNPs. $4 \mathrm{~nm}$ GNPs were stabilised with a mixed layer of phthalocyanine (a photosensitiser) and PEG, then further functionalised with anti-HER2 antibodies. This strategy successfully demonstrated selective targeting of HER2 + tumour cells. Furthermore, irradiation with visible red light generated localised cytotoxic singlet oxygen, demonstrating the potential of therapeutic photodynamic agents[56]. AntiHER2 conjugated gold nanoclusters have also demonstrated selective targeting of HER2+ expressing tumour cells producing a respective 3-fold and 9-fold increase in DNA damage compared to Herceptin and gold nanoclusters alone[57]. Alternative antibody based functionalization's include selective targeting of cell lines with overexpressed epidermal growth factor receptor, further conjugated with ${ }^{125} \mathrm{I}-$ radionuclide as a potential in vivo therapy platform, with bio distribution assays successfully demonstrating accumulation of GNPs at the tumour site as well as the spleen and thyroid[58]. CTimaging has also been enhanced using anti-EGFR functionalized GNPs with the whole tumour area 
averaging at 190 Hounsfield units (HU) compared to 78 with non-targeted GNPs and 34 HU without GNPs in tumour bearing mice[59].

\section{Maximising Intracellular Gold Nanoparticles}

Promoting specific sub-cellular targeting may further enhance GNP therapeutic efficacy. Typically GNPs entering the cell are endocytosed via clathrin coated vesicles, which fuse with endosomes then progress towards lysosomal degradation and exocytosis. Endosomal disruption motifs have been conjugated to the surface of GNPs to disrupt the endocytotic pathway, a process which differs depending on the functionalization of the GNP[60] but generally results in exocytosis [61]. Endosomal escape mechanisms have become increasingly popular in order to increase intracellular distribution and therapeutic surface area and allow organelle targeting. Lysosomotropic agents such as chloroquine and sucrose have been shown to disrupt endosomal membranes, increasing availability of DNA delivery agents[62], and intracellular GNPs[63]. Nanoparticle functionalization's have attempted to replicate this with some success, TAT-functionalised GNPs were found freely in the cytosol, managing to successfully negotiate intracellular barriers, due to the rapid escape of particles from the endocytic system or by direct translocation of the particles across the plasma membrane, or indeed both [64]. Other successful options include analogues of viral proteins such as H5WYG, taken from the n-terminal segment of the HA-2 subunit of the influenza virus haemagglutinin[65], and membrane disruptive polymers such as polyethyleneimine (PEI) which rupture the endosomal membrane upon acidification via the proton sponge effect[66].

Functionalization's to target the mitochondria have shown promise with mesoporous silicaencapsulated gold nanorods successfully accumulating at the organelle when a cytochrome c aptamer was employed, as demonstrated in figure 3. Near-IR treatment results in the release of the cytochrome $\mathrm{C}$ at the mitochondria site, promoting apoptotic pathways. Importantly, this multifunctional platform could integrate targeting, light-triggered release, and chemo-photothermal therapy into one system[67]. It has also been suggested that cetyltrimethylammonium bromide (CTAB) functionalised gold nanorods accumulate at the mitochondria following the exposure of residual CTAB on the nanorods surface when exposed to the acidic lysosomal microenvironment. The effect was caused by the delocalized positively 
charged head group in $\mathrm{CTAB}$ being attracted to the negative transmembrane potential from the mitochondria, ultimately promoting cell death through nanorods-induced mitochondrial damage, disrupting cell metabolism and ATP production[68].

Maximising the differential mass absorption co-efficient between high $\mathrm{Z}$ materials (such as gold) and soft tissue represents the underlying principle for using GNPs as radiosensitizers. In this setting, secondary electron emission and elevated $\bullet \mathrm{OH}$ yields promote the formation of potentially lethal DNA double strand break lesions. Therefore, targeted delivery of GNPs using nuclear localisation signals (NLS) represents a potential solution to further enhance therapeutic efficacy, provided the endosomal barrier can be bypassed. Additionally there is significant evidence to indicate that GNPs promote cell cycle arrest in the G2/M phase, a stage in cell development associated with increased levels of sensitivity to DNA damaging agents, including chemo and radiotherapy due to a breakdown of the nuclear envelope and separation of the chromosomes.[69]:[70]. The addition of a NLS to GNPs will further exploit these therapeutic advantages and has been shown to enhance chemosensitivity in human oral squamous carcinoma cells HSC-3 with cell viability reducing from $40 \%$ with $500 \mu \mathrm{M} 5$ fluorouracil (5-FU) to $17 \%$ when $30 \mathrm{~nm}$ NLS GNPs were added[71]. The NLS allows an increased efficiency of the GNPs to localise to the nucleus, enabling the 5-FU to inhibit thymidylate synthase resulting in an S-phase accumulation and cell death. In addition, the pre-treatment of cells with GNPs for $24 \mathrm{~h}$ prior to 5 -fluorouracil treatment resulted in an increase of late apoptosis and necrosis. While the molecular mechanisms for GNP-induced cell cycle alteration still need to be determined this does indicate that GNPs can be used both in combination with chemotherapy and radiotherapy. A pre-clinical study employed gold nanorods functionalised with PEG, poly(amidoamine) and the chemotherapeutic drug doxorubicin followed by photothermal irradiation $48 \mathrm{~h}$ post-injection in BALB/c mice. Intracellular release of doxorubicin improved tumour growth delay by 4-fold compared to tumour ablation alone, with cell death attributed to DNA damage through intercalation and heating of the tumour to $46^{\circ} \mathrm{C}[72]$. Multiple therapies applied from a single GNP possess major benefits for patients receiving both treatments simultaneously, however, significant research efforts continue to demonstrate the efficacy and safety of these multi-therapeutic 


\section{Conclusions}

Nanoparticles are set to dramatically impact future medicine, and with GNPs currently under wide scrutiny for an array of therapeutic roles as highlighted within this review. Understanding the synthesis and potential functionalization of gold nanoparticles opens an enormous range of possibilities for clinical therapy including cancer treatment, but problems remain. Multi-functionalised GNPs become increasingly more complicated and balance must be achieved between suitable in vivo stability, tumour localisation, limited cytotoxicity and efficacy. The complexity in achieving this balance is clearly illustrated by the lack of clinical trials conducted with gold nanoparticles to date, something that must be addressed to truly establish the potential benefit of these increasingly complex nanoparticles. Despite this, increased interest and publications is leading to an acceleration of all nanoparticle research and well thought-out and robustly tested GNPs certainly have the potential to make a big impact on tumour diagnosis and treatment.

\section{Future Perspective}

Nanoparticles are becoming increasingly complex in a bid to achieve multiple aims simultaneously. Functionalization's that address stability, cell uptake/targeting and therapeutic payload are commonplace and the current focus for many research groups. The next 5-10 years will feature far more of this style of nanoparticle development as the focus shifts towards multiple synergistic combination therapies using nanoparticles in combination with existing therapeutics. Indeed, many of these GNPs can also benefit diagnostic imaging tools such as CT-tomography creating a powerful theranostic application for cancer patients. Currently, the chemistry and functionalisation steps exist for this to be a reality, but robust characterisation alongside pre-clinical and clinical testing is needed. The next decade should see increasingly rapid advancements towards this goal, with more GNPs entering clinical trials.

\section{Executive Summary}


Chemical Synthesis of Gold Nanoparticles

- Reliable and reproducible GNPs can be produced through the Turkevitch/Frens method, while smaller GNPs can be synthesised via the Brust/Schiffrin method, however these are harder to functionalize.

Functionalization of Gold Nanoparticles

- Various attachments can be chemically conjugated to the GNP through ligand exchange/substitution or electrostatically, alternatively linker molecules can be employed. Functionalisation's are often dependant on the functional groups at both the GNP surface and the desired ligand.

- Problems persist with ligands binding to self or irreversible nanoparticle aggregation all of which needs to be robustly checked through comprehensive characterisation methods.

Gold Nanoparticle Stability

- Long-term storage of GNPs in solution and any in vivo or clinical application require further stability, preventing agglomeration and increasing blood circulation time and tumour accumulation. Further work is needed in determining the optimum stability agent as well as its surface coverage, molecular weight etc.

Cellular Uptake of Gold Nanoparticles

- Targeted delivery of GNPs to the tumour site is essential in future preparations as well as breaching the cell membrane. This can be achieved through CPP's to promote endocytosis and achieve higher intracellular concentrations of GNPs.

- Precise functionalisation could eventually be personalised depending on individual patient genetic profiling, validated targets and downstream applications.

Maximising Intracellular Gold Nanoparticles 
- A range of peptides exist to promote endosomal escape or specific sub-cellular or organelle targeting. The use of these will depend on the intended therapy and other functionalization's to ensure an effective and self-complimentary nanoparticle.

\section{Conclusions}

- The available options in designing a cancer therapeutic GNP are huge with a wide array of options and studies needed. The rate of research in this area however is increasing and with it the volume of available data.

- Robust characterisation and clinical trials are needed to truly advance GNP research, but the potential is enormous. 


\section{References}

1. Praetorius NP, Mandal TK. Engineered nanoparticles in cancer therapy. Recent Pat. Drug Deliv. Formul. 1(1), 37-51 (2007).

2. Fang RH, Hu C-MJ, Luk BT, et al. Cancer cell membrane-coated nanoparticles for anticancer vaccination and drug delivery. Nano Lett. 14(4), 2181-8 (2014).

3. Hainfeld JF1, Smilowitz HM, O'Connor MJ, Dilmanian FA SD. Gold nanoparticle imaging and radiotherapy of brain tumors in mice. nanomedicine. 8(10), 1601-9 (2012).

4. Numnuam A, Thavarungkul P, Kanatharana P. An amperometric uric acid biosensor based on chitosan-carbon nanotubes electrospun nanofiber on silver nanoparticles. Anal. Bioanal. Chem. (2014).

5. Imen Miladi, Christophe Alric, Sandrine Dufort, et al. The In Vivo Radiosensitizing Effect of Gold Nanoparticles Based MRI Contrast Agents. Small. 10(6), 1116-1124 (2014).

6. Libutti SK, Paciotti GF, Byrnes A a, et al. Phase I and pharmacokinetic studies of CYT-6091, a novel PEGylated colloidal gold-rhTNF nanomedicine. Clin. Cancer Res. 16(24), 6139-49 (2010).

7. Gad SC, Sharp KL, Montgomery C, Payne JD, Goodrich GP. Evaluation of the toxicity of intravenous delivery of auroshell particles (gold-silica nanoshells). Int. J. Toxicol. 31(6), 58494 (2013).

8. Regulla DF, Hiebert LB, Seidenbusch M. Physical and Biological Interface Dose Effects in Tissue due to X-Ray- from Metallic Gold Surfaces1 Induced Release of Secondary Radiation. Radiat. res. 50 (17), 92-100 (1998).

9. Herold DM, Das I, Stobbe C, Iyer RV, Chapman JD. Gold microspheres: a selective technique for producing biologically effective dose enhancement. J. Radiat. 76(10), 1357-1364 (2000).

10. Stevenson PC. A study of the nucleation and growth processes in the synthesis of colloidal gold. Discuss. faraday Soc. 11(c), 55-75 (1951).

11. Alric C, Taleb J, Le Duc G, et al. Gadolinium chelate coated gold nanoparticles as contrast agents for both X-ray computed tomography and magnetic resonance imaging. J. Am. Chem. Soc. 130(18), 5908-15 (2008).

12. Juurinen I, Pylkka T. Effect of the Hydrophobic Alcohol Chain Length on the Hydrogen- Bond Network of Water. J. Phys. Chem. 118(29), 8750-8755 (2014).

13. Kumar D, Meenan BJ, Mutreja I, D'Sa R, Dixon D. Controlling the Size and Size Distribution of Gold Nanoparticles: a Design of Experiment Study. Int. J. Nanosci. 11(02), 1250023 (2012).

14. Ojea-jime I, Romero FM, Bastu NG, Puntes V. Small Gold Nanoparticles Synthesized with Sodium Citrate and Heavy Water: Insights into the Reaction Mechanism. J. Phys. Chem. 114 , 1800-1804 (2010). 
15. Okitsu K, Sharyo K, Nishimura R. One-pot synthesis of gold nanorods by ultrasonic irradiation: the effect of $\mathrm{pH}$ on the shape of the gold nanorods and nanoparticles. Langmuir. 25(14), 7786-90 (2009).

16. $\tilde{A}$ TS, Ueda J, Nakamura A, Cho S, Saito N, Takai O. Gold Nanoparticle Synthesis Using Three-Dimensionally Integrated Micro-Solution Plasmas. Jpn. J. Appl. Phys. 52, 126202 (2013).

17. Philip D. Green synthesis of gold and silver nanoparticles using Hibiscus rosa sinensis. Phys. E Low-dimensional Syst. Nanostructures. 42(5), 1417-1424 (2010).

18. Zhou M, Wang B, Rozynek Z, et al. Minute synthesis of extremely stable gold nanoparticles. Nanotechnology. 20(50), 505606 (2009).

19. Zhao P, Li N, Astruc D. State of the art in gold nanoparticle synthesis. Coord. Chem. Rev. 257, 638-665 (2013).

20. Li Y, Zaluzhna O, Xu B, Gao Y, Modest JM, Tong YJ. Mechanistic insights into the BrustSchiffrin two-phase synthesis of organo-chalcogenate-protected metal nanoparticles. J. Am. Chem. Soc. 133(7), 2092-2095 (2011).

21. Farren-Dai M, Awoonor-Williams E, MacNeil CS, Mahimwalla Z, Ghandi K. A novel gold nanoparticle stabilization and its muon chemistry. Chem. Phys. Lett. 610-611, 331-334 (2014).

22. Ye X, Jin L, Caglayan H, et al. Improved size-tunable synthesis of monodisperse gold nanorods through the use of aromatic additives. ACS Nano. 6(3), 2804-17 (2012).

23. Cho W-S, Cho M, Jeong J, et al. Size-dependent tissue kinetics of PEG-coated gold nanoparticles. Toxicol. Appl. Pharmacol. 245(1), 116-23 (2010).

24. Kumar D, Meenan BJ, Dixon D. Glutathione-mediated release of Bodipy® from PEG cofunctionalized gold nanoparticles. Int. J. Nanomedicine. 7, 4007-22 (2012).

25. Virginia Tech Intellectual Properties, Inc. US 8,558,019 B2 (2013)

26. Nativo P, Porta F, Brust M. A Multidentate Peptide for Stabilization and Facile Bioconjugation of Gold. Bioconjug. Chem. 20, 619-624 (2009).

27. Slocik JM, Govorov AO, Naik RR. Plasmonic Circular Dichroism of Peptide-Functionalized. Nano Lett. 11, 701-705 (2011).

28. Tsai D-H, Cho TJ, Elzey SR, Gigault JC, Hackley V a. Quantitative analysis of dendronconjugated cisplatin-complexed gold nanoparticles using scanning particle mobility mass spectrometry. Nanoscale. 5(12), 5390-5 (2013).

29. Mirkin CA. Gold Nanoparticles for Biology and Medicine. 49(19), 3280-3294 (2014).

30. Gupta RK, Srinivasan MP, Dharmarajan R. Synthesis of 16-Mercaptohexadecanoic acid capped gold nanoparticles and their immobilization on a substrate. Mater. Lett. 67(1), 315-319 (2012). 
31. Stobiecka M, Coopersmith K, Hepel M. Resonance elastic light scattering (RELS) spectroscopy of fast non-Langmuirian ligand-exchange in glutathione-induced gold nanoparticle assembly. J. Colloid Interface Sci. 350(1), 168-77 (2010).

32. Astruc D, Liang L, Rapakousiou A, Ruiz J. Click dendrimers and triazole-related aspects: catalysts, mechanism, synthesis, and functions. A bridge between dendritic architectures and nanomaterials. Acc. Chem. Res. 45(4), 630-40 (2012).

33. Boisselier E, Diallo AK, Salmon L, Ornelas C, Ruiz J, Astruc D. Encapsulation and stabilization of gold nanoparticles with "click" polyethyleneglycol dendrimers. J. Am. Chem. Soc. 132(8), 2729-42 (2010).

34. Song Y, Xu X, MacRenaris KW, Zhang X-Q, Mirkin C a, Meade TJ. Multimodal gadoliniumenriched DNA-gold nanoparticle conjugates for cellular imaging. Angew. Chem. Int. Ed. Engl. 48(48), 9143-7 (2009).

35. Bishop KJM, Wilmer CE, Soh S, Grzybowski B a. Nanoscale forces and their uses in selfassembly. Small. 5(14), 1600-30 (2009).

36. Nanocrystals G, Huang X, Peng X, et al. A Reexamination of Active and Passive Tumor Targeting by Using Rod-Shaped. ACS Nano. 4(10), 5887-5896 (2010).

37. Kirui DK, Rey D a, Batt C a. Gold hybrid nanoparticles for targeted phototherapy and cancer imaging. Nanotechnology. 21(10), 105105 (2010).

38. Blood R, Counts C, Simpson CA, et al. Short-Chain PEG Mixed Monolayer protected gold clusters increases clearance and red blood cell counts. ACS Nano. 5, 3577-3584 (2011).

39. Paciotti GF, Kingston DGI, Tamarkin L. Colloidal gold nanoparticles: a novel nanoparticle platform for developing multifunctional tumor-targeted drug delivery vectors. Drug Dev. Res. 67(1), 47-54 (2006).

40. Brown SD, Nativo P, Smith J-A, et al. Gold nanoparticles for the improved anticancer drug delivery of the active component of oxaliplatin. J. Am. Chem. Soc. 132(13), 4678-84 (2010).

41. Dreaden EC, Mwakwari SC, Sodji QH, Oyelere AK, El-Sayed M a. Tamoxifen-poly(ethylene glycol)-thiol gold nanoparticle conjugates: enhanced potency and selective delivery for breast cancer treatment. Bioconjug. Chem. 20(12), 2247-53 (2009).

42. Shyh-Dar L, Huang L. Stealth Nanoparticles: High Density but Sheddable PEG is a Key for Tumor Targeting. J Control Release. 145(3), 178-181 (2011).

43. Fang J, Nakamura H, Maeda H. The EPR effect: Unique features of tumor blood vessels for drug delivery, factors involved, and limitations and augmentation of the effect. Adv. Drug Deliv. Rev. 63(3), 136-51 (2011).

44. Wang M, Thanou M. Targeting nanoparticles to cancer. Pharmacol. Res. 62(2), 90-9 (2010).

45. Hao Y, Yang X, Song S, et al. Exploring the cell uptake mechanism of phospholipid and polyethylene glycol coated gold nanoparticles. Nanotechnology. 23(4), 045103 (2012). 
46. Chen H, Paholak H, Ito M, et al. "Living" PEGylation on gold nanoparticles to optimize cancer cell uptake by controlling targeting ligand and charge densities. Nanotechnology. 24(35), 355101 (2013).

47. Liu T, Thierry B. A solution to the PEG dilemma: efficient bioconjugation of large gold nanoparticles for biodiagnostic applications using mixed layers. Langmuir. 28(44), 15634-42 (2012).

48. Liu X, Huang H, Jin Q, Ji J. Mixed charged zwitterionic self-assembled monolayers as a facile way to stabilize large gold nanoparticles. Langmuir. 27(9), 5242-51 (2011).

49. Herd H, Daum N, Jones AT, Huwer H, Ghandehari H, Lehr C-M. Nanoparticle geometry and surface orientation influence mode of cellular uptake. ACS Nano. 7(3), 1961-73 (2013).

50. Coulter JA, Jain S, Butterworth KT, et al. Cell type-dependent uptake, localization, and cytotoxicity of $1.9 \mathrm{~nm}$ gold nanoparticles. Int. J. Nanomedicine. 7, 2673-2685 (2012).

51. Trono JD, Mizuno K, Yusa N, Matsukawa T, Yokoyama K, Uesaka M. Size, Concentration and Incubation Time Dependence of Gold Nanoparticle Uptake into Pancreas Cancer Cells and its Future Application to X-ray Drug Delivery System. J. Radiat. Res. 52(1), 103-109 (2011).

52. Peckys DB, Jonge N De. Gold Nanoparticle Uptake in Whole Cells in Liquid Examined by Environmental Scanning Electron Microscopy. Microsc. Microanal. 20(1), 189-197 (2014).

53. Yuan H, Fales AM, Vo-Dinh T. TAT peptide-functionalized gold nanostars: enhanced intracellular delivery and efficient NIR photothermal therapy using ultralow irradiance. J. Am. Chem. Soc. 134(28), 11358-61 (2012).

54. Fales AM, Yuan H, Vo-Dinh T. Cell-penetrating peptide enhanced intracellular Raman imaging and photodynamic therapy. Mol. Pharm. 10(6), 2291-8 (2013).

55. Oh E, Delehanty J, Sapsford K, et al. Cellular Uptake and Fate of PEGylated Gold Nanoparticles Is Dependent on Both Cell Penetration peptides and Particle Size. ACS Nano. 5(8), 6434-6448 (2011).

56. Stuchinskaya T, Moreno M, Cook MJ, Edwards DR, Russell D a. Targeted photodynamic therapy of breast cancer cells using antibody-phthalocyanine-gold nanoparticle conjugates. Photochem. Photobiol. Sci. 10(5), 822-31 (2011).

57. Wang Y, Chen J, Irudayaraj J. Nuclear targeting dynamics of gold nanoclusters for enhanced therapy of HER2+ breast cancer. ACS Nano. 5(12), 9718-25 (2011).

58. Marega R, Karmani L, Flamant L, et al. Antibody-functionalized polymer-coated gold nanoparticles targeting cancer cells: an in vitro and in vivo study. J. Mater. Chem. 22(39), 21305 (2012).

59. Tobi Reuveni, Menachem Motiei, Zimam Romman A, Popovtzer RP. Targeted gold nanoparticles enable molecular CT imaging of cancer : an in vivo study. Int. J. Nanomedicine. 6, 2859-2864 (2011).

60. Bartczak D, Nitti S, Millar TM, Kanaras AG. Exocytosis of peptide functionalized gold nanoparticles in endothelial cells. Nanoscale. 4(15), 4470-2 (2012). 
61. Chithrani BD, Stewart J, Allen C, Jaffray D a. Intracellular uptake, transport, and processing of nanostructures in cancer cells. Nanomedicine Nanotechnology, Biol. Med. 5(2), 118-127 (2009).

62. Lévy R, Shaheen U, Cesbron Y, Sée V. Gold nanoparticles delivery in mammalian live cells: a critical review. Nano Rev. 1, 1-18 (2010).

63. See V, Free P, Cesbron Y, et al. Cathepsin L Digestion of Nanobioconjugates upon endocytosis. ACS Nano. 3(9), 2461-2468 (2009).

64. Krpetić Z, Saleemi S, Prior I a, Sée V, Qureshi R, Brust M. Negotiation of intracellular membrane barriers by TAT-modified gold nanoparticles. ACS Nano. 5(6), 5195-201 (2011).

65. Martens TF, Remaut K, Demeester J, De Smedt SC, Braeckmans K. Intracellular delivery of nanomaterials: How to catch endosomal escape in the act. Nano Today. 9(3), 344-364 (2014).

66. El-Sayed A, Futaki S, Harashima H. Delivery of macromolecules using arginine-rich cellpenetrating peptides: ways to overcome endosomal entrapment. AAPS J. 11(1), 13-22 (2009).

67. Ju E, Li Z, Liu Z, Ren J, Qu X. Near-infrared light-triggered drug-delivery vehicle for mitochondria-targeted chemo-photothermal therapy. ACS Appl. Mater. Interfaces. 6(6), 4364 70 (2014).

68. Wang L, Liu Y, Li W, et al. Selective targeting of gold nanorods at the mitochondria of cancer cells: implications for cancer therapy. Nano Lett. 11(2), 772-80 (2011).

69. Roa W, Zhang X, Guo L, et al. Gold nanoparticle sensitize radiotherapy of prostate cancer cells by regulation of the cell cycle. Nanotechnology. 20(37), 375101 (2009).

70. $\mathrm{Xu} \mathrm{W}$, Luo T, Li P, et al. RGD-conjugated gold nanorods induce radiosensitization in melanoma cancer cells by downregulating $\alpha(\mathrm{v}) \beta_{3}$ expression. Int. J. Nanomedicine. 7, 915-24 (2012).

71. Mackey M a, El-Sayed M a. Chemosensitization of cancer cells via gold nanoparticle-induced cell cycle regulation. Photochem. Photobiol. 90(2), 306-12 (2014).

72. Li X, Takashima M, Yuba E, Harada A, Kono K. PEGylated PAMAM dendrimer-doxorubicin conjugate-hybridized gold nanorod for combined photothermal-chemotherapy. Biomaterials. 35(24), 6576-84 (2014). 


\section{Figure legends.}

Figure 1. Common methods for gold nanoparticle synthesis. A - Turkevitch/frens method producing citrate capped GNPs by the reduction of $\mathrm{HAuCl}_{4}$ using trisodium citrate dehydrate. $\mathrm{B}$ - BrustSchiffrin method, using sodium borohydride as the reducing agent.

Figure 2. Field emission transmission electron microscopy images of MDA-MB-231 cells exposed to $12 \mu \mathrm{M}$ of $1.9 \mathrm{~nm}$ gold nanoparticles. Panel 1 represents gold nanoparticles confined to endosomes within the cytoplasm. Panel 2 demonstrates an invaginated clathrincoated pit with electron-dense material coating the cell membrane. Panels 3 and 4 represent intranuclear regions containing high-electron material. Arrows indicate gold nanoparticles and gold nanoparticle aggregates. Reprinted with permission from author and publisher ${ }^{50}$

Figure 3. Figure 3 - Gold nanorods encapsulated in mesoporous silica and functionalised with cytochrome c aptamer. A - Schematic diagram of functionalised nanorods. B - TEM of functionalised gold nanorods. C - Mitochondrial targeting of FITC-gold nanorods-cyt c aptamer in HeLa cells. Mitochondria are stained with Mitotracker red. Reproduced (adapted) with permission from (Ju E, Li Z, Liu Z, Ren J, Qu X. Near-infrared light-triggered drug-delivery vehicle for mitochondria-targeted chemo-photothermal therapy. ACS Appl Mater Interfaces. 2014;6(6):4364-70). Copyright (2014) American Chemical Society 
Figure 1 - Common methods of Gold Nanoparticle Synthesis

A<smiles>[Y19]OC(O[Y19])C(O)(CC(=O)[O-])CC(=O)[O-]</smiles>

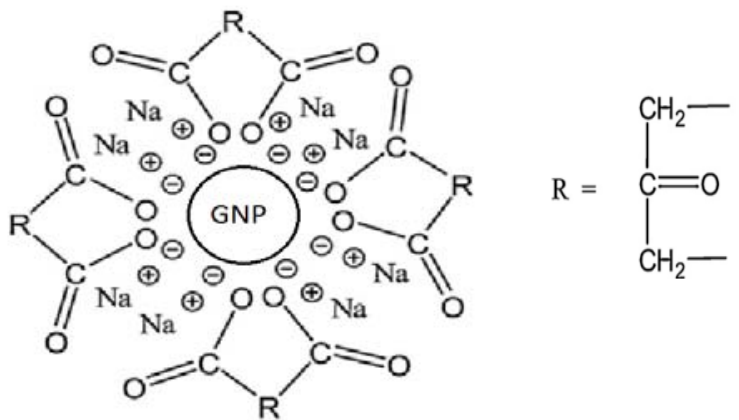

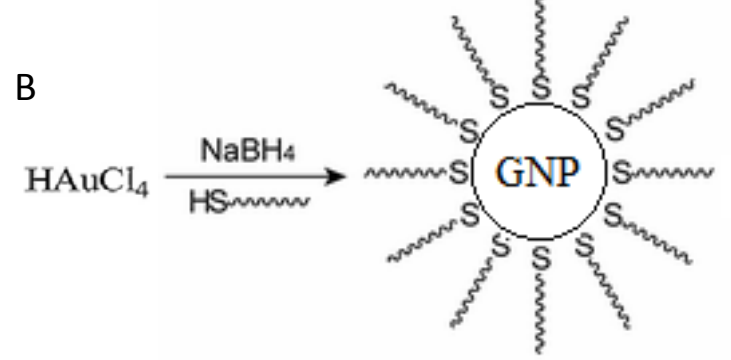


Figure 2 - TEM images of intracellular ultrasmall GNPs
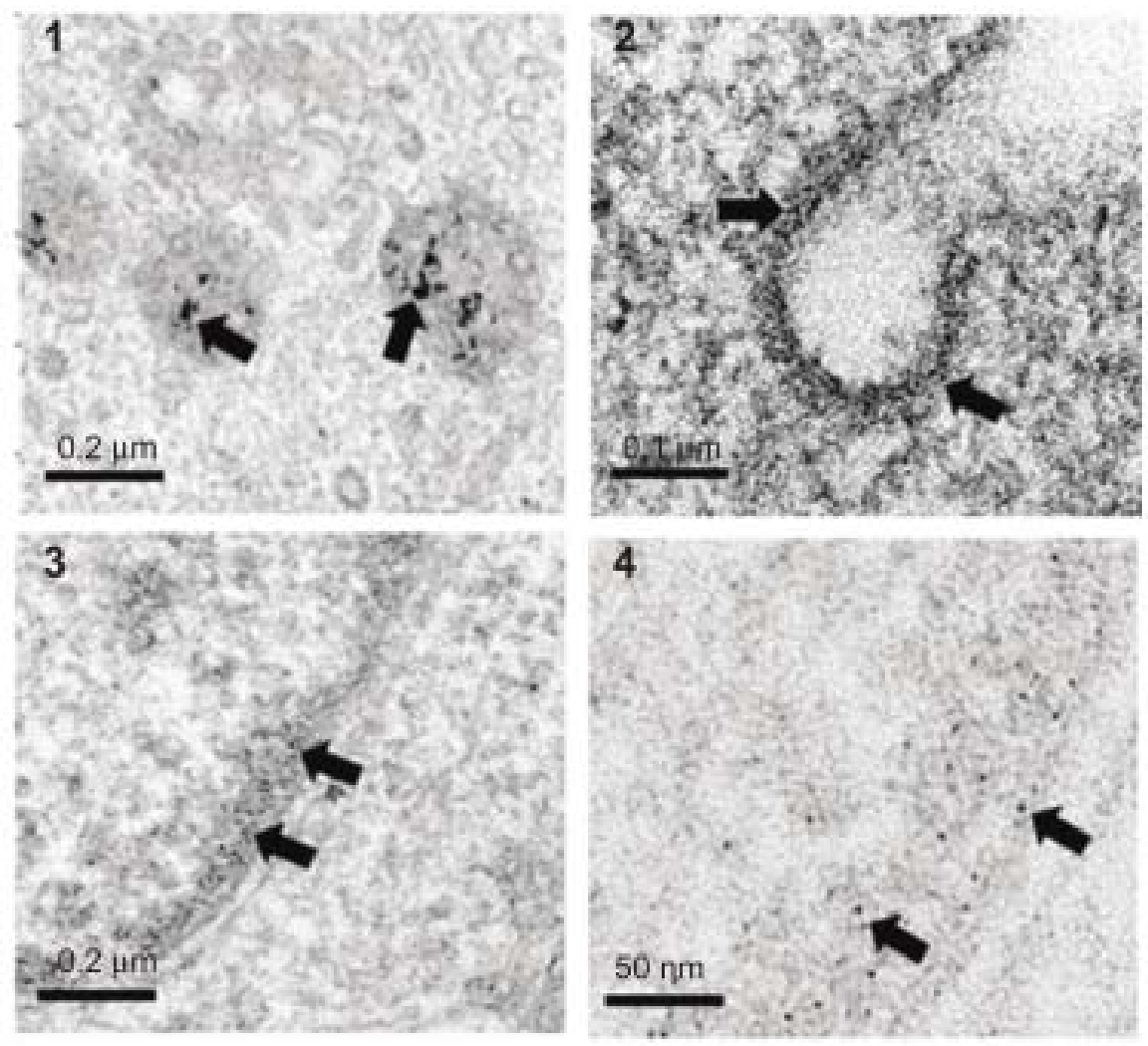
Figure 3-Mesopourous silica-encapsulated gold nanorods functionalised with cytochrome c

A
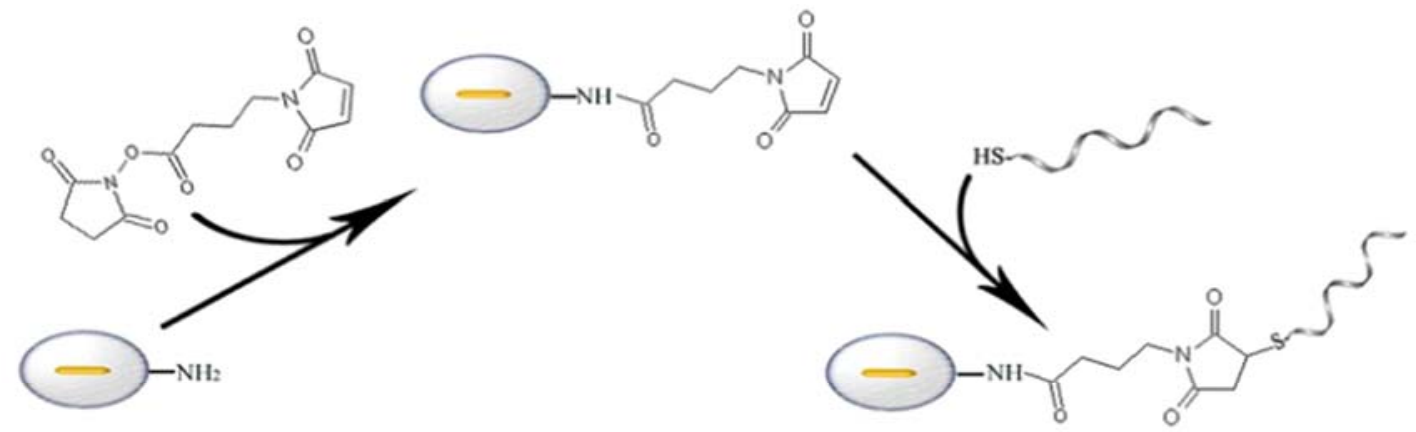

$\hookrightarrow A u$ Rod

Mesoporous Silica $\backsim \frown$ Cyt c aptamer

B

$\mathrm{C}$
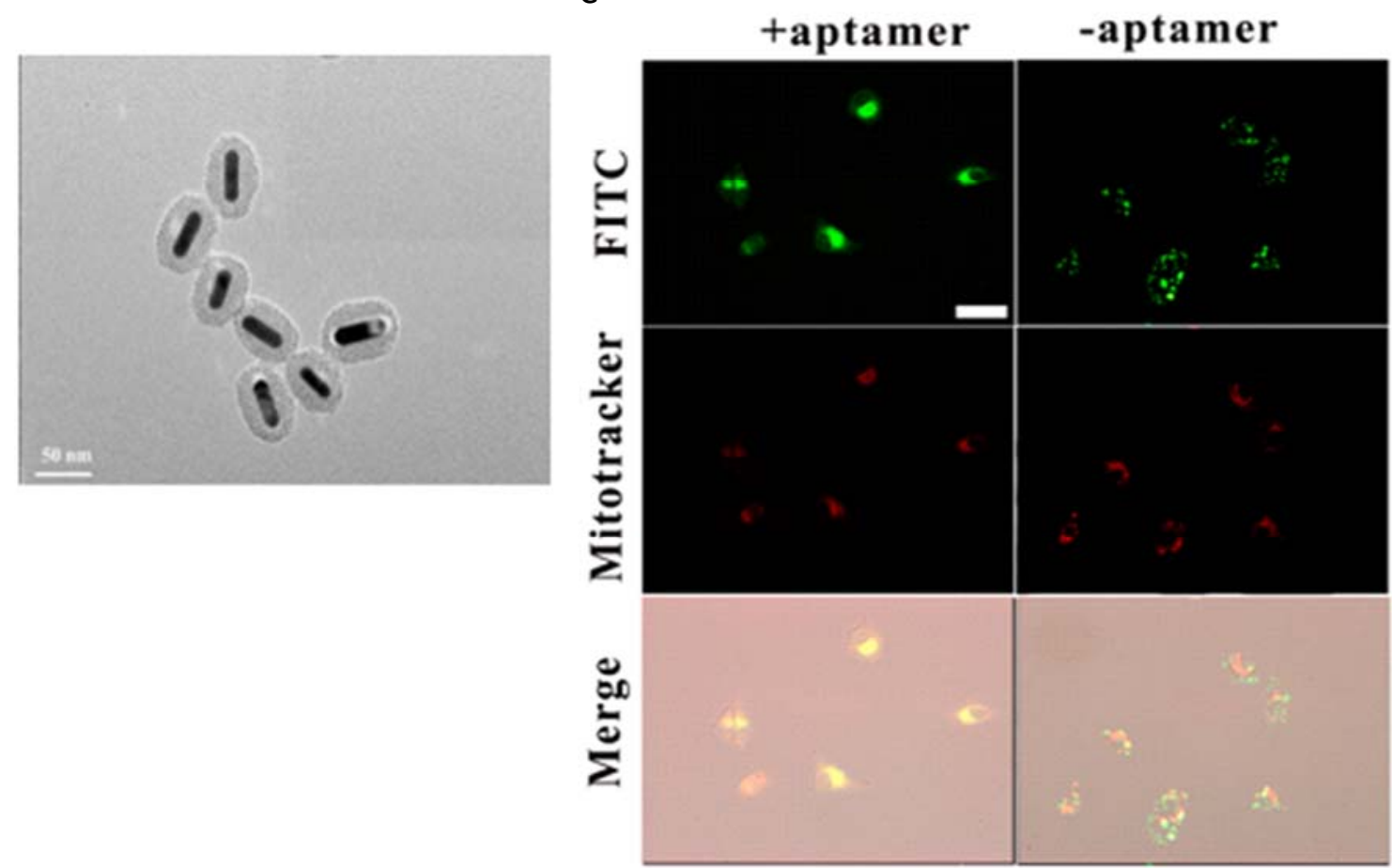
Table 1 - Bottom-up methods of gold nanoparticle synthesis

\begin{tabular}{|c|c|c|c|c|}
\hline $\begin{array}{l}\text { GNP Synthesis } \\
\text { Method }\end{array}$ & Principle & Advantages & Disadvantages & Reference \\
\hline Turkevitch/Frens & $\begin{array}{l}\text { Reduction of chloroauric acid with } \\
\text { trisodium citrate }\end{array}$ & $\begin{array}{l}\text { - } \\
\text { - } \\
\text { Trimple and highly reproducible citrate acts as a stabilising } \\
\text { capping agent } \\
\text { - Widely used and reviewed in the literature } \\
\text { with possible alterations depending on } \\
\text { desired end product }\end{array}$ & $\begin{array}{l}\text { - Unreliable synthesis of GNPs larger than } \\
35 \mathrm{~nm} \\
\text { - Moderate reducing ability of trisodium } \\
\text { citrate results in GNPS } \geq 10 \mathrm{~nm} \\
\text { - Citrate capping confers no stability } \\
\text { benefits in blood serum, high densities } \\
\text { and varying physiological conditions }\end{array}$ & [11] \\
\hline Brust/Schiffrin & $\begin{array}{l}\text { Reduction of chloroauric acid by } \\
\text { sodium borohydride }\end{array}$ & $\begin{array}{ll}\text { - } & \text { Allows synthesis on GNPS } \leq 5 \mathrm{~nm} \\
\text { - } & \text { Highly reproducible with high air and } \\
& \text { thermal stability } \\
\text { - } & \text { Relatively easy to manipulate through } \\
\text { surface ligand substitution }\end{array}$ & $\begin{array}{l}\text { - Does not allow synthesis of larger GNPS } \\
\text { - A separate capping agent must be used } \\
\text { to confer stability such as } \\
\text { benzyldimethyltetradecylammonium } \\
\text { chloride }\end{array}$ & [19] \\
\hline Pulse-radiolysis & $\begin{array}{l}\text { Reduction of Gold (III) chloride } \\
\text { through gamma-ray irradiation } \\
\text { producing radicals through ionization } \\
\text { of the solvent. A radical scavenger is } \\
\text { introduced to generate a new } \\
\text { stronger radical incapable of } \\
\text { oxidizing the gold ions, but provide } \\
\text { strong reducing power }\end{array}$ & $\begin{array}{l}\text { Allows the production of bimetallic } \\
\text { nanoparticles (e.g. Au-Ag-NPs) }\end{array}$ & $\begin{array}{l}\text { More difficult synthesis method, } \\
\text { requiring specialised equipment } \\
\text { - Not widely used in the literature }\end{array}$ & {$[20,80]$} \\
\hline Seed-growth & $\begin{array}{l}\text { Small GNP seeds (e.g. 3-4 nm citrate- } \\
\text { capped GNPs) are prepared and } \\
\text { added to a 'growth' solution } \\
\text { containing chloroauric acid, mild } \\
\text { reducing agents and stabilising } \\
\text { agents. Fresh growth solution can be } \\
\text { used to further the growth process. }\end{array}$ & $\begin{array}{l}\text { Greater control over GNP size (up to } 300 \\
\text { nm) } \\
\text { - A highly customizable growth solution, } \\
\text { allowing relatively easy synthesis of } \\
\text { alternate GNP geometries } \\
\text { Established protocols are reproducible, } \\
\text { producing stable, mono-disperse GNPs }\end{array}$ & $\begin{array}{l}\text { - Careful monitoring needed of variables } \\
\text { such as temperature, pH, Au precursors } \\
\text { and reducing agent concentration } \\
\text { - Various shapes often produced as by- } \\
\text { products, reducing the desired GNP- } \\
\text { shape yield } \\
\text { - High levels of customizable steps make } \\
\text { this method potentially more } \\
\text { complicated }\end{array}$ & {$[20,81]$} \\
\hline
\end{tabular}


Table 2 - common examples of CPP's

\begin{tabular}{|c|c|c|c|}
\hline CPP & Origin & Sequence & Reference \\
\hline TAT & $\begin{array}{c}\text { HIV-1 } \\
\text { transcriptional } \\
\text { activator }\end{array}$ & GRKKRRQRRRPPQ & $\begin{array}{c}\text { Vives } \\
(1997)^{74}\end{array}$ \\
\hline Penetratin & $\begin{array}{c}\text { Drosophila } \\
\text { melanogaster }\end{array}$ & RQIKIWFQNRRMKWKK & $\begin{array}{c}\text { Derossi } \\
(1994)^{75}\end{array}$ \\
\hline Polyarginine & synthetic & Rothbard \\
& $\begin{array}{c}\text { Fusion of } \\
\text { neuropeptide } \\
\text { galanin-1-12 } \\
\text { and wasp } \\
\text { venom peptide } \\
\text { mastoparan via } \\
\text { lys }\end{array}$ & GWTLNSAGYLLGKINLKALAALAKKIL & $\begin{array}{c}\text { Pooga } \\
(1998)^{77}\end{array}$ \\
\hline RME & $\begin{array}{c}\text { Adenovirus } \\
\text { MAP }\end{array}$ & CKKKKKKSEDEYPYVPN & \\
\hline & KLALKLALKALKAALKLA & $\begin{array}{c}\text { Liu } \\
(2007)^{78}\end{array}$ \\
\hline
\end{tabular}

